\title{
Research on the Evaluation System of Service Quality in High-star Hotels Based on Relation Matrix of Fuzzy Mathematics and Analytic Hierarchy Process
}

\author{
Ling Zhu \\ Institute of Tourism, Central South University of Forestry and Technology, Changsha, 412004, \\ China \\ zh_u_ling@126.com
}

Keywords: relation matrix; evaluation factors; weight vector; evaluation system; fuzzy mathematics; analytic hierarchy process

\begin{abstract}
Service quality is the lifeline of service industry, More and more hotel began to establish perfect service quality evaluation system. Inorder to supervise and control the quality of the service of the hotel.this paper Aiming at the Service Quality of Changsha High-star Hotels Evaluation System.Through the customer evaluation, hotel organization evaluation and the third party assessment empirical. In-depth analysis of high-star hotels in changsha city,quality evaluation system operation status and existing problems.On this basis the fuzzy AHP in changsha city for the construction of high-star hotels service quality evaluation optimization system puts forward strategic decision.
\end{abstract}

\section{Introduction}

In recent years, hotel service quality evaluation gets a very good development as a branch of service quality evaluation. The research of service quality evaluation is always accompanied by the understanding of service quality. Due to the intimate contact between service quality and customer satisfaction, from the perception of customer service to understand and evaluate,the quality of service is widely recognized.There is a lot of research in this field,especially in foreign,it started earlier.For example, Parasuramn (1985) is based on this kind of understanding,so that he puted forward the service quality evaluation method-SERVQUAL, which were recognized by most scholars [1]. Yun Lok Lee (1995) used the SERVQUAL scale to measure and compare the hotel service quality ,in order to evalue the validity and application of the SERVQUAL[2]; Lopez Fernandez and M.C, Serrano, a. (2004) had used the SERVQUAL model to investigate the Spanish restaurant, the research showed that the hotel star rating could not reflect the hotel service quality very well[3].In the domestic, the related research also has a lot ,such as HeYaLan Puts forward the concept of hotel service quality evaluation system,through the construction and application research of the hotel service quality evaluation system,and from the evaluation subject, evaluation object, evaluation media three aspects summarizes hotel service quality of the whole system[4]. Although there is a lot of theory research in this domain, whether the evaluation system is practical and effective, and achieve a truly evaluation and supervision of the service quality ,it needs to have a constant observation and adjustment.

\section{The operation situation of evaluation system in Changsha high-star hotels}

In this paper,it uses present situation investigation and analysis of the Changsha High-star Hotels Evaluation System .Ozn the current,it is constituted by the evaluation of main body(the customer, the organization and the third party) and the object body (hardware service quality and software service quality),the main body is composed of three main modules, and the object body is composed of two main modules. The specific composition is as below.

As shown in Figure 1,there are three kinds of main body in Changsha High-star Hotels Evaluation System: Customer (hotel service recipients, the service object of all the hotel staffs) whose evaluation of the hotel service quality reflects the satisfaction and loyalty to the hotel service;hotel organization(hotel service providers) whose own service quality evaluation can understand the provided service quality of the products, the market adaptability,and the level of the service products' profit. Investigation shows that all the Changsha High-star Hotels are equipped with the quality 
inspection department which is specifically responsible for the hotel staff service quality, at the same time every department also appraise its service quality. Besides, a lot of the hotel also specially invites experts for the evaluation of the quality of hotel service;The third party(it neither represents the customers interests of the accepting service,nor the enterprise benefit of service providers,but the independent of the hotel service supplier and home-textile evaluation main body). By the investigation ,it shows that the third party of the evaluation of the hotel service quality is mainly newspapers and magazines,network evaluation and the supervision of the competent department of tourism and so on. The object body of the Changsha High-star Hotels Evaluation System is mainly concentrated on two aspects: hardware service quality and software service quality. The specific composition is shown below:

TABLE I. The Composition of the Changsha High-star Hotels Evaluation System’s object body

\begin{tabular}{|c|l|l|}
\hline \multirow{4}{*}{$\begin{array}{c}\text { The hardware } \\
\text { service quality }\end{array}$} & $(1)$ & Hotel facilities \\
\cline { 2 - 3 } & $(2)$ & Service supplies \\
\cline { 2 - 3 } & $(3)$ & Physical products \\
\cline { 2 - 3 } & $(4)$ & Overall environment \\
\hline \multirow{3}{*}{$\begin{array}{c}\text { The software } \\
\text { service quality }\end{array}$} & 1 & Service consciousness \\
\cline { 2 - 3 } & $(2)$ & Service attitude \\
\cline { 2 - 3 } & $(3)$ & Service methods and skills \\
\hline
\end{tabular}

As is shown in Table 1, hardware service quality includes hotel facilities and service products (in the process of service tray, towel, dish bowl, embroidered words bath robe, etc),physical products

(welcome fruit, good night milk, free porridge,the selling goods in mini market:such as socks, dental floss, shampoo, bath liquid, nail clippers, etc) and the overall environment ,etc. Software service quality includes staff service consciousness (language manners, and tidy dressed ), service methods and skills(service efficiency), service attitude(employees responsibility,Service initiative,service enthusiasm).

\section{The Problems of the Changsha High-star Hotels Evaluation System}

A. The Current Media Analysis of the Changsha High-star Hotels Service Quality Evaluation

Evaluation media is a evaluation form and the evaluation of main body which reflect the channel of evaluation results. The following contents through the different evaluation of the main body illustrates each subject specific evaluation form of the current media analysis of the Changsha Highstar Hotels service quality evaluation. The specific process is as below:

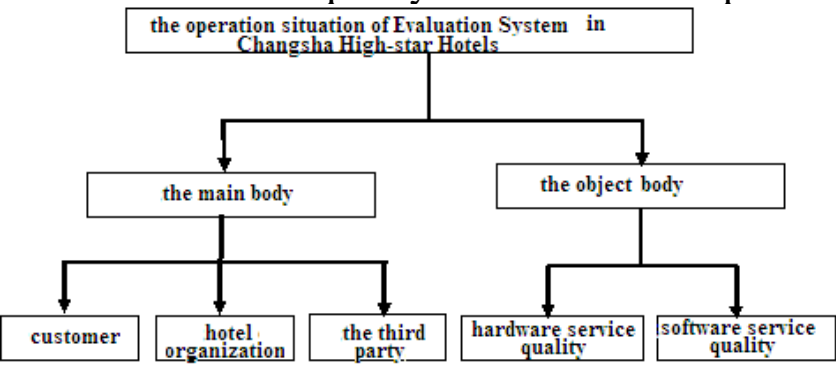

Figure 1.
The Operation Situation of Hotels

Evaluation System in Changsha High-star

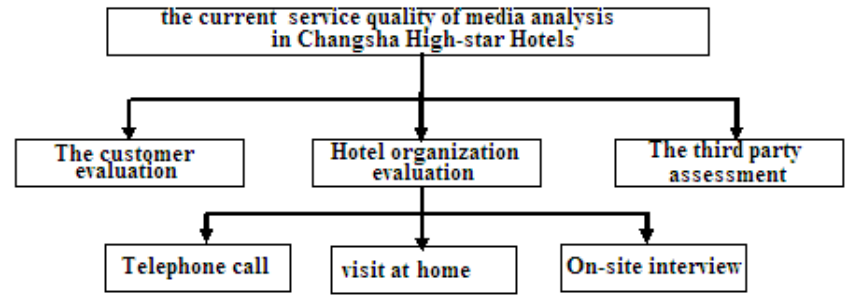

Figure 2. The specific evaluation form of the current evaluation media of the Changsha High-star Hotels service quality

As shown in Figure 2 , the specific evaluation form of the current evaluation media of the Changsha high-star hotels service quality is mainly consist of three parts: firstly is the customer evaluation(praise and complaints), through the praise, complaints, complaint to show evaluation of the hotel service quality; secondly is hotel organization evaluation . It mainly includes the evaluation of the competent employees on daily work service quality by the supervisor,and the combination with performance evaluation and salary adjustment, and at the same time, the hotel will also survey the customers service quality evaluation .The main methods are telephone call,called on,on-site visit[5]. Thirdly is the third party assessment, mainly using web site comments channel, BBS, the introduction and the evaluation on newspapers and magazines, the evaluation report of the competent department of tourism's used hotel service quality, evaluation sessions,the industry Selection will organised by the departments .

B. The problem analysis of the current Changsha high-star hotels service quality evaluation 
system

In order to have a better comprehensive, systematic and clear understanding of the condition of the Changsha high-star hotels service quality evaluation system and provide scientific basis for the research of our service quality evaluation system ,we have a deep interview on the hotel staff and customers ,and have a investigation to the present situation of the operation hotel service quality evaluation system. After the questionnaire survey ,and in order to make more scientific statistics, this investigation used the basic method ---stratified sampling[6].It took the random method , issuing 5000 questionnaires ,and backing 3654,the effective questionnaire 3360 copies. Then we chose 3360 questionnaires of 1000 as a random sample, the investigation shows that the problems of the Changsha high-star hotels service quality evaluation system mainly reflects in the following factors, the specific is as below:

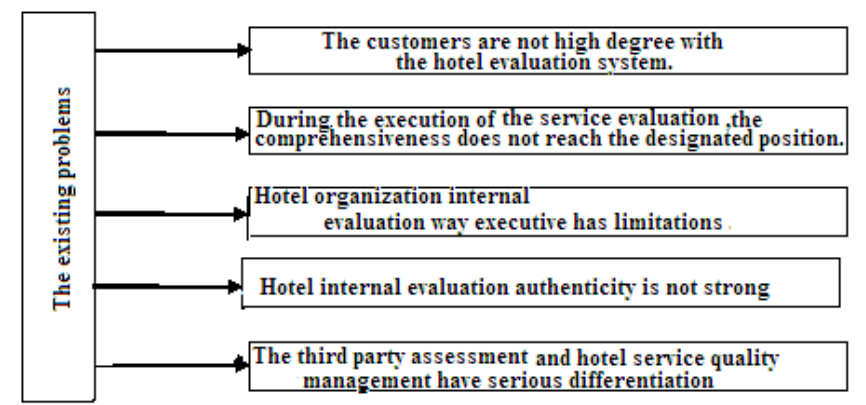

Figure 3. The problems of the current Changsha high-star hotels service quality evaluation system

As shown in Figure 3 ,there are five problems in the current Changsha high-star hotels service quality evaluation system[7]. Firstly, the guests' subjective consciousness is not strong,so that the customers are not high degree with the hotel evaluation system.Secondly, due to subjective reasons of the staff and the management during the survey of the customer service quality ,it may lead to a incomprehensive evaluation content, which results in that the comprehensiveness does not reach the designated position during the execution of the service evaluation. Thirdly, there are three ways to survey the hotel service departments on customers service quality (telephone call, to visit and the quality of service access). Each have limitations,so that it leads to the limitations of hotel organization internal evaluation way executive[8].Fourthly, the hotel in the evaluation of the organization are generally prior notice,that is to say, the service quality is a status that appraiser arrange in relatively full preparation, thus the hotel internal evaluation authenticity is not strong.Lastly, the staff don't understand the assessment of the hotel's third party, and the hotel managers don't agree with the evaluation standard and evaluation content of the third party service quality evaluation ,and they think the evaluation standard is not suitable for the actual operation needs.At the same time, the hotel also does not take corresponding measures to deal with the third party assessment ,thus, the third party assessment and hotel service quality management have serious differentiation .

\section{Optimizing the evaluation system of service quality in Changsha high-star hotels}

It needs to have a fuzzy comprehensive evaluation to optimize the evaluation system of service quality in Changsha high-star hotels[9]. The specific is that through the construction class fuzzy subset quantify the fuzzy indexes which reflect the appraised things(determining the membership ). Then we make the use of the fuzzy transform principle to synthesize each index.

(1) Determining the factors field of the evaluation object evaluation index: $u=\left\{u_{1}, u_{2}, \cdots \cdots, u_{p}\right\}$, at the beginning of the investigation of the hotel service quality to customers,the hotel can Unified design out the service contents of the quality problems and ask method, assigning the competent department for unified training. Determining the evaluation object factors should notice the following main areas:

A Facilities, including building and decoration, facilities of equipment, materials, supplies, environment and atmosphere, etc;

B Staff service quality, including staff service level, the service attitude and service effect, etc;

$\mathrm{C}$ The level of management, including the special service requirements and emergency response speed and processing ability, to deal with complaints and processing capacity, etc; 
D The quality of the staff, including image poise, polite attitude, professional level and psychological quality, etc.

In the actual operation process, based on the above requirements investigate content to have a improvised communication with guests, thus to obtain the required information. During the communication ,the employees should also pay attention to leave well enough alone,we should not achieve the purpose of survey and ignore the customer feeling, in order to avoid the customer feel bored.

(2) Determining the comments field level $v=\left\{v_{1}, v_{2}, \cdots \cdots, v_{p}\right\}$,that is level set, Each level can correspond to one fuzzy subset.it can take the necessary measures to induce and stimulate the customer to actively participate in evaluation,so that it can keep continuous measurement of continuity.

(3) To establish fuzzy relation matrix $R$

After optimizing the Changsha high-star hotels service quality evaluation system,it needs to quantify the appraised things from every factors $u_{i}(i=1,2, \cdots \cdots, p)$,determining the grade fuzzy subset of membership from single factor $\left(R \mid u_{i}\right)$, and then getting the fuzzy relation matrix[10]:

$$
R=\left[\begin{array}{cc}
R \mid & u_{1} \\
R \mid & u_{2} \\
\cdots & \\
R \mid & u_{p}
\end{array}\right]=\left[\begin{array}{cccc}
r_{11} & r_{12} & \cdots & r_{1 m} \\
r_{21} & r_{22} & \cdots & r_{2 m} \\
\cdots & \cdots & \cdots & \cdots \\
r_{p 1} & r_{p 2} & \cdots & r_{p m}
\end{array}\right]_{p . m}
$$

The $\mathrm{i}$ line of the $\mathrm{R}$ matrix in the $\mathrm{j}$ column element,sugests that the grade fuzzy subset of membership from single factor .A appraised thing in certain ${ }^{u_{i}}$ factors' performance is depicted by the fuzzy vector $\left(R \mid u_{i}\right)=\left(r_{i 1}, r_{i 2}, \cdots \cdots, r_{i m}\right)$. At the same time the hotel should add the managers of the service quality "dark review" to avoid the inveracious effect of the public investigation .While in other evaluation methods, it is more described by a actual value index ,so it requires more information from the point of view of fuzzy comprehensive evaluation .

(4) Determining the evaluation factors of the weight vector

In the fuzzy comprehensive evaluation, it determines the evaluation factors of the weight

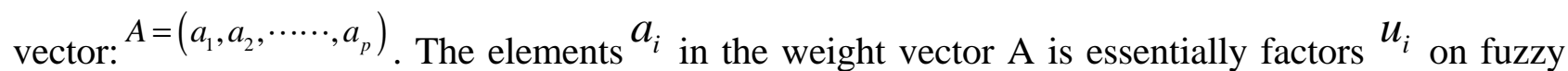
membership . This article used analytic hierarchy process (AHP) to determine evaluation index among the relative importance order. Department management organise s corresponding training, leting employees know the third party evaluation form, content, so as to determine weight coefficient, and synthetic before the normalization,it is[11]:

$$
\sum_{i=1}^{p} a_{i}=1, a_{i} \geq 0 \quad i=1,2, \cdots \cdots, n .
$$

(5) The results vector of synthetic fuzzy comprehensive evaluation

By using the appropriate operator A,we can synthesize the appraised thing to get the fuzzy comprehensive evaluation result of the vector of the appraised thing $B$. The hotels strengthen the related communication with a third party to guide the third party having the correct and effective evaluation on hotel service quality . At the same time, it should make the third party assessment as a reference between a customer evaluation and hotel organization evaluation .The customer evaluation and hotel organization evaluation in the execution process according to the third party assessment way and content to improve itself, thus it can get more objective service quality evaluation.it is as below[12]:

$$
A \circ R=\left(a_{1}, a_{2}, \cdots \cdots, a_{p}\right)\left[\begin{array}{cccc}
r_{11} & r_{12} & \cdots & r_{1 m} \\
r_{21} & r_{22} & \cdots & r_{2 m} \\
\cdots & \cdots & \cdots & \cdots \\
r_{p 1} & r_{p 2} & \cdots & r_{p m}
\end{array}\right]=\left(b_{1}, b_{2}, \cdots \cdots, b_{m}\right)=B
$$

Among them, ${ }^{b}$ is composed of the J column operation between A and R. It shows on the whole the appraised thing on the level fuzzy subset of the degree of membership. Completing appraisal 
report, in order to reflect the result of assessment, and let the appraisal report as the bases of hotel quality management results and staff rewards and punishment for promotion .

\section{Conclusion}

As a hotel service providers, the hotel need to evaluate the service quality themselfes to know their own quality of the provided services products, market adaptability and service product profit level,meanwhile, the high-star hotels are equipped with the quality inspection department which is specifically responsible for the hotel staff service quality, and each department should take an examination of each other. Besides ,the hotel also need to establish a good relationship with the third party, and invite experts to have a evaluation of the hotel service quality, rationally utilize the effective resource to construct a optimizing changsha high-star hotel service quality evaluation system.

\section{References}

[1] Bao Hui, Hu Pei, Hu Bin.Service quality analysis and evaluation research.Soft science, 2010(3):23-26.

[2] DangZhongcheng,ZhouZhili. Hotel service quality measurement and improvement. Journal of tourism, 2012(2):11-15.

[3] LiCaijuan, LiChunhua, WangLijun. Fuzzy decision in the application of the service quality evaluation.Journal Hebei construction engineering college,2011 (2):55-59.

[4] HeYalan. Hotel service quality evaluation system construction and its application research.Overseas Chinese university master thesis , 2009(12):13-16.

[5] CuiZhehao.The measure of empirical research on star internal service quality model.Journal of tourism, 2012(8):136-139.

[6] XiongWei, XuJunHua.The content analysis of China's economy hotel service quality evaluation research--- and with high-star hotel relative ratio. Beijing second foreign language university, 2010(11):45-49

[7] ZhenranGao. Measuring quality in restaurant operations:an application of the SERVQUAL instrument.Hospitality Management,2011 (3):93-97.

[8] López Fernández,M. C,Serrano,A. M. Bedia. The hotel classification system is a good indicator of hotel quality-An application in Spain.Tourism Management,2008 (8):771-775.

[9] Tat Y. Choi,Raymond Chu. Determinants of hotel guests' satisfaction and repeat patronage in the Hong Kong homl industry.Hospitality Management,2011,20(3):277-297.

[10] Michael Lynn . Restaurant tips and service quality:a weak relationship or just weak measurement.Hospitality Management,2011,22(4):321-325.

[11] Sheng-Hshiung Tsaur,Yi-Chun Lin. Promoting service quality in tourist hotels:the role of HRM practices and service behavior.Tourism Management,2009,25(5):471-475.

[12] EnlaiYen,LunSu.Customer satisfaction measurement practice in Taiwan hotels[J]. Hospitality Management,2011,23(5):39-40. 